The 5th International Symposium on Robotics in Construction June 6-8, 1988 Tokyo, Japan

\title{
CURRENT STATE OF AUTOMATION AND ROBOTICS IN CONSTRUCTION
}

\author{
Shankar Sundareswaran \& David Arditi \\ Illinois Institute of Technology \\ Department of Civil Engineering \\ Chicago, Illinois, USA.
}

\begin{abstract}
The use of robots is growing in the manufacturing industries. But in field-oriented industries like construction, adaptation to automation technologies has been slower. The most progress to date in automation for construction has been made in the control of temporary on-site plants for batching concrete, bending reinforcement steel, and making pre-cast concrete elements. However in order to automate construction processes more effectively, it will be necessary to develop methods and approaches for design that recognize the characteristics of construction machinery. The objective of this paper is to examine the needs and potential of automation and robotics technologies and review the state-of-the-art in selected automation related areas.
\end{abstract}

\section{INTRODUCTION}

Robot as defined by the Robot Industry of America is a mechanical device that can be programmed to perform task of manipulation and locomotion under automatic control. Employment of robots is growing in the manufacturing industries. But in field-oriented industries like construction, adaptation to automation technologies has been slower. According to Robotics Industry Association (RIA) reporis, the installed base of robots in the United States has grown from about 6300 units in 1982 to 20,000 in 1985 [1]. Sustained growth is expected not only in the automotive industry which has always been the leader in robot usage, but also in other industries. On the other hand, the point is also made that the population of robots in U.S has fallen far short of forecasts made early in the decade and that a $\$ 2$ billion industry is likely to develop by 1990 .

Robots are available in a broad range of sizes and configurations, with a variety of control features and in different price ranges, all reflecting users' needs. Enhancements such as vision, sensors, and communication systems are increasingly used. A sure sign of industry maturity is the serious work being done by several committees under the auspices of RIA to develop standards for design and performance. They are aggressively seeking to improve their products and broaden their capabilities to assure that robots are established as essential automation tools.

Too often the robot has been looked on merely as a human replacement subjected to workstation environments with all the judgmental, dexterous, and accommodating skills inherent in the human; subjected also to the same conditions that contribute to the human operator's low productivity and poor quality of output. In a very real sense, the robot is an enforcer and integrator, forcing the manufacturer to look at how material is moved from place to place, how process operations are organized, how quality is built into each operation and monitored, and more. In this sense, the robot becomes an integrator of a variety of advanced manufacturing technologies.

There are times when contractors wish that a crew of metal men would march on site and toil 
tirelessly. Those days may never come, and robols may never completely replace construction workers. But a new generation of robots, already rolling onto construction sites in Japan, has the potential to shrink manpower requirements, boost productivity and relieve human workers of hazardous and repetitive work. Like their industrial kin, construction robots don't look like metal men. They look like highly sophisticated machines; they are machines that bring computing power, sensors and automation to construction tasks. Some machines already used on construction projects such as automated paving machines, tunnel-boring machines, scarpers with computerized transmission controls, instrumented drills and others have sensors and some processing abilities that bring them nearly within the realm of robotics [2].

The objective of this paper is to examine the needs and potential of these technologies; to review the state-of-the-art in selected areas; to briefly define, examine and classify the various technologies; to identify technical, economic and institutional barriers to making the technologies an attractive goal and practical reality for industries like construction; and to stimulate potential researchers with the qualifications and interest to advance this field.

\section{NEEDS AND PROSPECTS OF ROBOTICS IN CONSTRUCTION}

The construction industry is an important part of the economy of every nation. The industry plays a significant role in promoting commerce, in improving health and quality of life, in providing for national defenses, and in supplying the infrastructure needed for shelter, public health, transportations, water supply, irrigation, power, eduacation and other functions of people's daily lives. The total volume of US construction output in 1986 was close to $\$ 400$ billion. Construction products have historically accounted for $55-65 \%$ of the country's total investment in Gross Fixed Capital Formation (GFCF); it employs over 4 million people, about $5 \%$ of the non-agricultural labor force nationwide; it represents $6-10 \%$ of the Gross National Products (GNP). Most construction volume is handled by 480,000 firms with payrolls, comprising 290,000 special trade contractors, 130,000 residential builders, 31,000 heavy construction contractors, and 37,000 non-residential building contractors. The industry also includes 720,000 firms with no employees, which account for a small percentage of construction revenues [22].

Despite its importance to the national economy and well-being, the US construction industry has undergone an alarming decline in productivity growth over the past two decades, from a healthy $3.4 \%$ per year during 1948-1965, to a drop of $-1.8 \%$ during the 1970's and 1980's [3]. The construction industry is also marked with low profit margins when compared to other industries. For example, 124 of the ENR top 400 US contractors reported total contracts of $\$ 136,119$ million with an average profit of $2.9 \%$ of their annual revenue [23]; in contrast, the Fortune 500 largest industrial corporations reported an average return on sales of $4.1 \%$ in the same year [26]. Furthermore, research and development acitivity in construction has traditionally been quite low. The current US construction related research and development by all elements of the construction community is less than $0.4 \%$ of sales; contractors, architects, and engineers contribute less than $0.05 \%$ as a group. This is a fraction of the amount spent on liability insurance alone [5].

Construction is a ripe, virtually untouched, and inevitable arena for robotics applications. The construction industry dwarfs manufacturing and other industries that have successfully embraced simpler automation. Labor efficiency is alarmingly low in construction, idle or ineffective worker time may exceed half the work week [3], productivity growth is declining [2], and competitive pressures are at an all time high [24]. There are inevitable physical human limitations that make construction workers vulnerable to hostilities such as severe weather, dust, vacuum, submersion, or cave-ins; and that prevents these workers from reaching ceilings, lifting pallets, bending steel, or crawling in pipes. Because construction is the most hazardous industry after mining, concern for health and safety provide additional impetus for robotic implementation. Other motivations include the need for better quality assurance for replacing vanishing craftmanship, and better progress control in the construction site of the future [25]. 
The sizable increases in productivities and corresponding decreases in real costs of construction from 1920 to 1970 were brought about primarily by mechanization of construction technology and the introduction of new types of heavy equipment between the 1920's and 1950's. From the 1950's to the 1970 's the primary improvements were due to increases in equipment power and capacity, and in the effectiveness with which equipment was used [22]. In the late 1980's significant advances are being made in the fields of electronics, signal and control systems, artificial intelligence, and material sciences and engineering. These advances may have an impact on increasing construction productivity, very much like what happened after the 1920's with the development and extensive use of heavy construction equipment. Computers, remote sensing, and diagnostics technology, automation and robotics, and engineered materials have advanced far enough to penetrate the construction industry, provided that pertinent research and development activity is geared in that direction.

\section{RECENT PROJECTS}

About 30,000 robots are employed today in countries like Japan, United States and Europe, most of them in machine tool processing, welding, palletizing, painting, casting, forging, loading and unloading etc. About half of these applications involve simple "pick and place" operations, and less than $10 \%$ of those use sensors for interaction with the environment.

Robots can be grouped into three classes according to the type of control procedure available, and their relation to human supervisors. The first of these classes, teleoperated robots, include machines where all planning, perception, and manipulation is controlled by humans; the Three Mile Island nuclear damage recovery system is a good example of strictly teleoperated robots. Programmed robots, the second of these classes, perform predictable, invariant tasks according to pre-programmed instructions; the magnetic mapping hardware is primarly programmed. Cognitive robots, the third class, sense, model, plan, and act to achieve working goals without intervention by human supervisors. REX possesses the first glimmerings of cognition and autonomy.

A widely accepted definition characterizes a robot as a reprogrammable, multi-functional manipulator designed to move materials, parts, tools, or specialized devices through variable programmed motions for the performance of a variety of tasks. This definition, valid to a point in the factory, excludes the high and low end capabilities of devices that are relevant in unstructured environments and deemphasizes the importance of mobility. The definition is inadequate in other ways as well. Teleoperated systems, though are not necessarily programmable, have proven themselves in unstructured environments [6]. Likewise, cognitive robots with reactive planning capabilities go beyond the classical definition of programmed machines by devising strategies on their own.

Experiences are too few and it is too early to resolve the relative importance of these classes or to discount the potential of any class. The Japanese have embraced the teleoperators and programmed machines for construction [6]. Perhaps the early American views of construction robotics overestimated the need for sensing, artificial intellegience, and autonomy. Still researchers speculate that these cognitive attributes will ultimately dominate construction robotics. Nonetheless, teleoperators and programmed machines have both short- and long-term relevance.

Teleoperation is proven where man does not tread, where demands are superhuman, where tasks are unstructured, where liability is high, and where action is inevitable. Likely short-term areas for teleoperated robots include space, sea, nuclear, mining, timbering, firefighting, and some construction. Teleoperated robots are generally suited to unsiructured tasks. The man-machine interface that is well developed in teleoperated robots will endure in other classes of robots too because humans need to interact with robots for the purpose of conveying goals, exchanging information, and influencing courses of action. A downside of teleoperation, however, is that much is lost in translation across the man-machine interface. Robot bodies and senses are optimal for coupling to man. However, human minds are not optimal for the control of robots because of limitations in input/output bandwidth, memory structures, and numerical processing. Hybrid forms of teleoperation and programmed machines are 
becoming increasingly attractive.

Construction robots require attributes for working in unstructured environments. Classes of robots are expected to emerge for different types of work that have different sets of constraints. Also, it is likely that some of the forms developed for other purposes will find revelance somewhere in construction, if only because construction's umbrella is so broad. Some of the most recent developments in construction robotics are presented below.

\section{Data Aquisition}

Recent work in video data acquisition was conducted by O' Brien [7], Paulson [8] and Koo [9]. Subsequent research to use microcomputers to partially automate the data extraction from film was conducted by Dorman [10], and Touran [11].

Basically, these methods require an analyst to focus in detail upon an ongoing operation to undersiand relationships between tasks and resources, quantify activity durations, determine reasons of delay, and identify imbalances in the operation design. Time-lapse film or videotape has advantages in reducing the labor required to capture data; they capture more data simultaneously and allow repeated viewing of the operation for different parameters and thus enable time compression.

Computer-based data aquisition is an area where the structural and geotechnical engineers have made considerable progress, but few have integrated analysis and design-based instrumentation into real-time construction engineering decision making. Some Japanese contractors have put considerable emphasis on intergrating and monitoring deep foundation excavation, offshore works, iunnels and similar structures [21]. Such instrumentation is widely used by the Japanese contractors to optimize major excavations.

Once the data is collected, it can be interfaced with microcomputer-based software for automatic collection, storage, retrieval, preprocessing, statistical classification and conversion of collected data for analysis, design, and control decision making. The construction industry already has experience with time-lapse and videotape camera recording data. These technologies are indirect, and have obvious disadvantages like time delay and semi-manual transcription for building manual or computer data files.

Of particular interest today is designing and testing interface software to integrate the raw data collected by electronic devices monitoring real-time physical systems and some of the powerful standard commercial software packages available for microcomputers.

\section{Automatic and Adapative Controls for Construction Equipment}

The need for automatic controls to increase the accuracy and operating speed of construction equipment is apparent if construction costs are to be kept down. Automatic control minimizes material consumption by holding close tolerances, and at the same time, reduces the cost of training the equipment operators.

Most major construction equipment manufacturers are experimenting with and even producing some machines that include on-board microprocessors for monitoring performance, maximizing engine power and fuel economy, optimizing gear shifts, keeping loads within safe tolerances, etc. As a result of two decades of operating experience and development supported by major advances in electronics and laser technology, laser based machine control systems have become the accepted method for achieving high accuracy and productivity in precision grading.

Using laser surveying equipment combined with electro-hydraulic feed back control systems mounted on bulldozers, motorgraders and scrapers, has helped in reducing costs in some cases over $80 \%$ and improving quality. In the 1970s, some government agencies and construction contractors helped 
pioneer these applications for partial automation [12].

The Japanese normally have automatic recorders attached to advanced soft-ground tunneling machines to record excavation volumes, advance rates, jack pressures, and other parameters to guide a "blind" tunneling operation [2]. A number of mining operations have used sensors to count vehicles, such as trucks, to estimate production volume, and optionally to direct trucks to ideal loaders.

The Komatsu Tractor Company has done considerable work in remote-controlled and amphibious and submersible bulldozers for work in coastal areas and hazardous environments [13]. They have also developed and implemented tunneling machines that incorporate a variety of sensing and control mechanisms to optimize tunnel excavation [14].

U.S equipment manufacturers are moving towards partial automation in their products by adding computer controls to machines to relieve operators of some part of the task. An excavator for example, could have an automatic " return to dig " program, or move the bucket back to a specified position without error after any other maneuver. Improvements like this could be saleable because they add productivity to the machine and make the work easier for the operator [2].

\section{Magnetic Mapping}

The Carnegie-Mellon Research Laboratory (CRL) is developing an intettigent magnetic sensing system to scan, size, and map embedded steel, thus making it possible to inspect and validate reinforcing bars in concrete and buried utility pipes. To perform this task, they hypothesize the geometry of ferrous objects by representing images, then infer from those images using image understanding methods. Their current implementation produces a skeletonized map with estimates of the buried steel's size and depth [6].

\section{Excavation}

Excavation is another excellent application to further the evaluation of construction robotics because of the significance in scale and economic importance. It operates on universal and generic material (soil), and an excavation's goal and state can be described adequately by robot models of geometry and kinetics. Further, excavation is tolerant of imprecision, well understood as a human driven process, and prototypical of a host of spin-off applications. A strong motivation for robotic excavation is the hazaro posed by explosive gases that are sometimes ignited during blind digging of gas utilities. Unmanned excavation may reduce the human injuries and property losses attributed to such explosions, decrease operation costs, and increase productivity of excavation in general [15].

The CRL has prototyped the first Robotic Excavator "REX", which integrates sensing modeling, planning, simulation, and action to unearth buried utility piping. Conventional strategies and traditional digging tools are unsuitable for this type of excavation because of the liability of pipeline damage. The benign end tooling developed for REX, however is a supersonic air-jet cutter that dislodges material without the direct contact intrinsic to bucket excavation. This non-contact tooling considerably reduces the potential for the system to damage itself and its environment.

REX manipulates the air-jet cutter mentioned above to excavate a site. A truck-mounted, four-link backhoe positions a six-link maipulator, the prototype for which is a rugged hydraulic arm with a thin aspect ratio to minimize the threat of collision. Together, the backhoe and the arm combine to deploy tooling throughout the excavation site. REX interprets sonar data to build an accurate surface model of the excavation site. The resulting depth is interpreted to detect target objects such as pipes, and to classify non-erodable features such as rocks or buried foundations. REX then consults this sensors-built surface model to plan digging operations. Based on surface topography and the presence and location of target pipes, digging trajectories are generated and executed [6]. 
This constitutes an early implementation of autonomous excavation without considering economic optimization. However the research has identified bottlenecks and deficiencies through the first implementation. They are currently improving tooling, manipulation, control, sensing, modeling, and strategy for a second-generation excavator with refinements on the original.

\section{Nuclear Damage Recovery}

Radiation environment are ideal areas for the evaluation of active working automations. Nuclear facility value is high, hazards are real, and increasingly stringent regulations limit human radiation exposure to "as little as resonably achievable". Nuclear damage recovery demands a subset of construction capabilities including surfacing, cutting, washing, material transport, and demolition, that are simple by comparison with those ultimately needed current state of art.

CRL has developed a Remote Core Sampler (RCS) to cut and retrieve concrete samples from the basement walls of the Three Mile Island Unit-2 reactor. The RCS deploys electro-hydraulic drills, at heights two to eight leet, that are precisely controllable in position, velocity, and thrusi; these drills drive two-stage, diamond-tipped coring tools. The inner bit cuts the core and the outer bit cuts an oversized kerf to enable easy sample breakoff. The RCS initially entered the TMI-2 containment building in November 1985 and successfully returned with the core samples for analysis. A comprehensive sampling program is now underway.

The Remote Work Vehicle is the system flagship for recovery work in the Three Mile Island Unit-2 basement. The RWV is especially ambitious in its capability, redundancy, reliability and decontaminability. It can de-water the basement, wash contaminated surfaces, remove sediments, demolish radiation sources, apply surface treatmenis, package materials, and transport these materials from the basement.

The RWV is conceived as a working juggernaut. It weighs over five ions. It features an omnidirectional, four wheel drive locomotor, a tiltable and extensible boom, and a servo-manipulator. It can tuck through the reactor's airlock and hatchway, and extend to reach twenty-five feet vertically. It performs over thirty motions and has nearly 200 controllable components including stifflegs, locomotion, boom, manipulator, lethering, and cameras [6].

\section{Assembling Wall Segments in Tunnels}

Ishikawajima-Harima Heavy Industry and Tokyo Electric Power Co. have jointly developed a robol designed to assemble wall segments in tunnels for sewerage systems and power cables. Under the conventional tunnel digging operations, concrete segments of the tunnel wall are assembled by human operators after an excavator machine digs the tunnel. It takes three to four workers about 50 minutes to assemble a single ring of wall segments for tunnels four to five meters in diameter. With the robot system, the same operation can be completed in 30 minutes with only one human operator needed to feed the segments to the robot system. The operating sequence of the robot system is as follows. A special conveyor system feeds wall segments to an automatic assembly machine: the machine, then, moves each segment to the proper place and aligns it with the bolt holes by using a hole detecting sensor: the bolt tightener inserts and tightens the nuts and bolts [16].

\section{Stone-Stacking in Residential Construction}

Tokyu Construction Co. has developed a stone-stacking robot designed to be used at construction sites for residential buildings. This robot was developed in Japan to cope with the rapidly aging work-force in the construction industry and also to reduce strenuous and hazardous working environments at 
construction sites. The robot basically consists of a backhoe whose tip is fitted with a robot grip incorporating three sensors. It is capable of carrying heavy concrete blocks to a designated area and install each block along the foundation for housing lots. In ordinary stone-stacking operations where human workers perform the task, a stone or concrete block of about 60 kilograms is loaded onto the bucket of a backhoe, and the blocks are carried to and unloaded at the construction site one by one by the workers. The robot hand equipped with three sensors is capable of handling up to five concrete blocks. Some of the features of this robot is its capability to handle stones or concrete blocks of virtually any shape and the backhoe can be used for other construction work after the stone laying task is completed. Tokyu is currently using the robot at its housing construction site in Kangawa Prefecture [17].

\section{Welding of Large Structural Elements}

Mitsubishi Heavy Industries has developed a heavy-duty welding robot designed for welding large structural blocks such as the panel blocks for cranes and bridges. Equipped with two welding heads, the 8 -axis numerically controlled robot performs welding operations from numerically controlled data extracted from a Computer Aided Design (CAD) system. It has five times the work capacity of human welders, according to Mitsubishi. The robots welding range is 5.8 meters wide and 32 meters long [18].

\section{Floor Finishing}

A self-propelled robot which cleans concrete floors at newly constructed buildings and also removes pieces of unwanted concrete chips from the floor has been developed by Shimizu Construction Co. The robot is made of a mobile cart and work modules for floor cleaning and chip removing. The robot itself incorporates various sensors and a computer that allows it to move about the concrete floor and perform its task without being taught any work procedure. It has a gyrosensor to confirm direction, a distance sensor to detect the exact distance travelled and ultrasonic and touch sensors to locate obstacles. Initially, the robot "inspects and sizes up" the work area by making a tour of the room by moving along the walls. And, then, it moves back and forth to cover the entire area while finishing the floor with the cleaning attachment or the chip remover. In cleaning operation, the robot can finish a 500 square meter floor in one hour, whereas it requires two cleaners to work a whole day to complete the same task. In chip removing the robot can perform its task at an average rate of 2 square meters per minute. Shimizu is planning to develop other robot modules to finish walls and ceilings [19].

\section{Spray-Painting Outer Surface Of Balcony Railings}

Shimizu Construction Co. has developed a paint-sprayer robot designed to paint the outer surface of balcony railings in high-rise buildings. A working prototype is currently being tested at a 15-story and 18-story condominium project in Shinagawa-ku, Tokyo. Painting the outer surfaces of guardrails of high-rise balconies is currently performed by human painters working on temporary scaffoldings or from movable platforms suspended from the roof. The selfpropelled robot is programmed to paint the railings from the balcony, reaching out and over the railing and spraying paint on the surface from the other side. Besides safety the advantage of using this robot is that it works with equal precision of a skilled painter. The system consists of a self-propelled unit that moves the robot along the rails, a control unit, horizontal and vertical arms. The robot swings its horizontal arm over the railing and guides an automated spray gun located on the tip of a vertical arm up and down along the guardrail supports. The spray gun is capable of painting in three types of patterns [16].

\section{Checking Wall Tiles on High Rise for Defects}

Taisei Corp., Japan's second largest construction firm, has developed a robot for checking loose and 
damaged tiles on walls of high rise buildings. Using a steel ball $1.8 \mathrm{~cm}$ in diameter, the robot lightly taps the tile surface while a sensitive microphone picks up the sound and has it analyzed to see whether or not the tile is defective. In addition to its ability to find loose tiles, the robot can find abnormalities 4 centimeters below the tiles. A built-in microcomputer, then computes the exact position of the defective tile and transmits the data to a printer located at the ground surface control center. While its working speed is no more than that of human inspectors, the overall inspection speed is four times faster than human inspection because the robot does not call for constructing scafoldings or installing and operating other equipment [20].

\section{CONCLUSION}

Construction activities are basically internal and external. The internal activities involve construction work within an enclosed structure and require robots with a load lifting capacity of an average worker; the required reach of the robot would be larger than that of a worker. The exterior activities invlove hauling larger loads within the construction site. The payloads and the reach required for these operations are well beyond the technologies available today. There is, however no reson why the regular construction equipment used today like cranes and pumps could not be integrated, with some modifications, into robotic systems.

The use of teleoperated robots in construction (as opposed to repair and maintenance) has limited application basically because of human shortcomings in the man-machine interface. A rigid preprogrammed mode without human supervision or continuous feedback from the environment is also of limited use in today's construction site, because of the complexity of building tasks, the rugged site conditions, and the high tolerance of most infrastructure components. Robots of the future will be required to operate in a constantly changing environment and be able to dynamically "sense" the outside world. Internal sensors will measure the inner variables that are important to robotic control and system well-being. External sensors will provide an interface with the environment and may include a number of devices, mechanisms, technologies, and vision systems that can produce feedback to regulate robot movements.

The potential for the development and use of advanced robotics in construction is promising; the necessary conditions for the deployment of such systems have been in place for the last 20 years. The potential impact on the national economy of improvements in the construction industry is a valid reason for funneling public and private research and development funds in this area. This way, it could be possible to stop the decline in construction productivity that occured in the last 20 years and achieve productivity increases like those experienced between 1920-1970. Factors like human limitations, safety considerations, better quality control, closer progress monitoring, and overcoming adverse environmental factors constitute additional reasons why robotic applications should be more common in the years to come. Computer technology, remote sensing, signal and control systems, artificial intelligence, and material science and engineering have advanced far enough to allow for the introduction of robotics technology into the construction industry. 


\section{REFERENCES}

1. Munson G. E., "Robotics in Perspective", Robotics Today, Society of Manufacturing Engineers, Vol.8, No. 2, Apr. 1986, pp. 29-31.

2. Japan Takes Early Lead in Robotics," Engineering News-Record, Vol. 211, No. 31, Jul. 21, 1983, pp. $42-45$.

3. Sanvido, V., Productivity Improvement Programs in Construction. The Construction Institute, Stanford University, Technical Report No. 273, Mar. 1983.

4. Moavenzadeh, F., "Construction High-Technology Revolution," Technology Review, Oct.1985.

5. Wilson, J. L., "Computer-Integrated Construction," Foundation Workshop on Construction Automation, Lehigh University, Working notes, Apr. 21, 22, 1987, p. 2.

6. William L. Whittaker "Cognitive Robots for Construction," Annual Research Review, The Robotic Institute, Carnegie-Mellon University, Pittusburgh, PA, pp. 7-17.

7. O' Brien, J.B., Knott, J.L., \& Woodhead R.W., "A system for Fully Automated Capture and Analysis of Field Performance Data," CIB W-65 Proceedings of the 4th International Symposium on Organization \& Management of Construction, Vol II, Waterloo, ON, Canada, 1984, pp. 445-454.

8. Pauison, B.C., Jr., Douglas, S.A., Kalk, A., Touran, A., \& Victor, G.A., "Simulation \& Analysis of Construction Operations," Journal of Technical Topics in Civil Engineering, ASCE, Vol. 109, No. 2, Aug. 1983, pp. 89-104.

9. Koo, C.C., "Video Data Processing System (VIP): An Operational Data Acquisition system", Thesis submitted to Stanford University, in Stanford, CA, in partial fullfillment for the degree of Engineer, 1984.

10. Dorman, W.F., Knott, J.L., \& Woodhead, R.W., CYCLONE-Timelapse Analysis System Introductory User Manual, School of Civil Engineering, University of New South Wales, Australia, Dec. 1980.

11. Touran, A., "Construction Operations Data Acquisition and Processing Via Time-Lapse Pholography Interfaced to a Microcomputer," Dissertation submitted to Stanford University, in Stanford, CA, in partial fullfillment of the requirements for the Degree of Doctor of Philosophy, 1980.

12. Ward, C.J., "Automotive and Adapative Controls for Construction Equipmenis," Paper 750765 Society of Automotive Engineers Off-Highway Vehicles Meeting, Milwaukeee, WI, Sep. 8-11, 1975.

13. Asano, J., Amphibious Bulldozer Construction Methods, Komatsu, Lid, Tokyo, Japan, 1978.

14. Shimomura, Y., \& Sonoda, T., "Tunneling by Robots: Shield Driving Automatic Control System," Proceedings of the Workshop Conference on Robotics in Construction, D. Sangrey ed., Carnegie Mellon University, Pittusburgh, PA, Jun. 17-20, 1984.

15. Whittaker, W., et al. "First Results in Automated Pipe Excavation." Proceedings of the Second International Conference on Robotics in Construction, CMU-RI-WC85-2, Jun. 1985.

16. "Robot Assembles Wall Segments in Tunnels," A Newsletter on Japan Robotics, Advanced American Technology Publishing, Inc., Mar. 20, 1985, p. 2.

17. "Tokyu Has Stone-Stacking Robot for Residential Construction Sites," A Newsletter on Japan 
Robotics, Advanced American Technology Publishing, Inc., Jun. 20, 1985, p. 1.

18. "MHI Develops Welding Robot for Large Structural Blocks," A Newsletter on Japan Robotics, Advanced American Technology Publishing, Inc., Jul. 20, 1985, p. 4.

19. "Shimizu Construction Unveils Robots for Floor Finishing," A Newsletter on Japan Robotics, Advanced American Technology Publishing, Inc., Oct. 20, 1985, p. 2.

20. "Robots Check Wall Tiles For Defects On High-Rise Buildings," A Newsletter on Japan Robo tics, Advanced American Technology Publishing, Inc., Aug. 20, 1985, p. 4.

21. Paulson, B.C., Jr., "Research in Japanese Construction Industry," Journal of the Construction Division, ASCE, Vol. 106, No. C01, Mar. 1980, pp. 1-16.

22. Moavenzadeh, F., "Innovation: Productivity and Competitiveness", Construction, Massachusetts Institute of Technology, Center for Construction Research and Education, Winter 1988, pp.1-3.

23. "US Recovery Fuels Work Again", Engineering News-Record, Vol. 216, No. 16, Apr. 17, 1986, pp. 58-64.

24. "Failures Hit 50 Years High", Engineering News-Record, Vol. 209, No. 11, Sep. 9, 1082 , p.68.

25. Bernold, L. E., "Automation and Robotics in Construction: a Challenge and a Chance for an Industry in Transition, International Journal of Project Management, Vol. 5, No. 3, Aug. 1987, pp. 155160.

26. "The Fortune 500 Largest US Industrial Corporations", Fortune, Vol. 115, No. 9, Apr. 27, 1987. 